\title{
Design, building and validating a measuring scale for the supply chain management practices of industrial organizations by assessing their efficiency on SCM measures
}

\author{
Wael Hassan El-Garaihy ${ }^{a^{*}}$, Usama A. Badawi ${ }^{\mathrm{b}}$, Walid A. S. Seddik ${ }^{\mathrm{c}}$ and M. Sh. Torky ${ }^{\mathrm{d}}$
}

${ }^{a}$ Associate Prof. of Management, Imam Abdulrahman Bin Faisal University, Kingdom of Saudi Arabia

${ }^{b}$ Assistant Prof. of Computer Science, Management Information Systems Department, Collage of Applied Studies and Community Service, Imam Abdulrahman Bin Faisal University, Kingdom of Saudi Arabia

${ }^{c}$ Lecturer of Management, Marketing Department, Collage of Applied Studies and Community Service, Imam Abdulrahman Bin Faisal University, Kingdom of Saudi Arabia ${ }^{d}$ Assistant Prof. of Mathematics, Collage of Applied Studies and Community Service, Imam Abdulrahman Bin Faisal University, Kingdom of Saudi Arabia

\section{A B S T R A C T}

\section{Article history:}

Received July 17, 2021

Received in revised format

September 22, 2021

Accepted October 192021

Available online

October 202021

Keywords:

Supply chain management

practices

SC performance measures

Industrial Organizations

Efficiency

\begin{abstract}
The aim of this study is to design, build and validate a scale for the measurement of Saudi industrial Organizations' SC Management Practices (SCMP), and also to evaluate its efficiency at various SCM measurements. The analysis identified 20 constructs of (SCMPs) based on a comprehensive literature review; namely Strategic Partnership of Suppliers (SPS), Customer Relationship (CR), Information Sharing (IS), Information Quality (IQ), Postponement (PST), Agreed Vision and Goals (AVG), Sharing of Risks and Rewards (SRR), Lean Manufacturing (LM), Total Quality Management (TQM), Organizational Culture (OC), Information and Communication Technology (ICT), Benchmarking and Performance Measurement (BPM), Agile Manufacturing (AM), Outsourcing (OUT), Just In Time Manufacturing (JIT), Green SC Management (GSCM), Reverse Logistics (RL), Vendor Managed Inventory (VMI), Radio Frequency Identification (RFID), and SC Integration (SCI), and four SCM performance structures in particular namely; Flexibility Perspective (FLP), Efficiency Perspective (EFP), Customer's Perspective (CSP), Product Innovation Perspective (PIP). A survey tool based on the existing literature was developed and relevant data were collected from 351 Industrial Saudi organizations on this tool. In the data analysis the validation of the instrument is mainly carried out with confirmatory factor analysis in terms of unidimensionality, durability, convergent validity, discriminant validity, nomological validity, and the associated validity criteria. A parsimonious instrument that makes an important contribution to the SCM literature is generated by the results of this research. The instrument will allow an enterprise to incorporate various SCMPs, to keep track of the implementation status, and then to evaluate SCM performance to the SCM dimensions.
\end{abstract}

\section{Introduction}

The new business model has changed from small companies to commercial networks like SCs. In this period of rivalry between networks, the position of the organization has shifted from a mere industry providing local companies to an international market operating in local companies (Rudberg \& Olhager, 2003). For companies to win or even prosper in this modern world, they must be competitive, by providing goods in the right place and at the right time. This is a dilemma for organisations, and it is now more than ever crucial that they cooperate to build key resources through the management and practice of their SC.

The SCM involves a range of activities applied within the enterprise to achieve and to improve efficiency through management, by an organization closely connected to the network, of finished products, commodities, and knowledge from 
the source of production to the point of use. SCM thus represents all operations related to SCs architecture, planning, harmonization, organization, and control (Chan et al., 2003). The core elements of SCM are described in a variety of ways: SC structure, SC business processes, and SC components. Taylor (2004) highlighted the dynamic flow of demand, supply, and cash as these components. Practices in the SC include supplier corporate relationships, client interactions, information exchange, consistency of information, and postponement (Li, Ragu-Nathan, Ragu-Nathan \& Subba Rao, 2006). The objective of these activities is to increase the competitiveness of the SC and improve the efficiency of the SC (Stonebraker \& Liao, 2004). Therefore, businesses that engage in this effort have to plan and adapt these practices to accomplish successful SCM to ensure the quality of operation and benefits, as well as to implement efficient management techniques.

SCM practices should be regarded in our dynamic, dominating world today as the collection of actions that organisations. Development today has shown the value of using creative efforts to cut prices, globalize capital, maintain short life cycles for the commodity, strengthen quality programs and satisfy the growing customization need (Taylor, 2004). In recent years, SCM has attracted increased interest in organizational performance from multiple professionals and scholars (Pandiyan Kaliani Sundram, Razak Ibrahim \& Chandran Govindaraju, 2011), which was deemed one of the most successful ways for organisations to achieve their strategic edge. It was also used as an important managerial instrument for companies to sustain the continuity, success, and profitability of their businesses.

The literature on SC has emphasized the need to consider SCMPs that are a prerequisite to sustaining the worldwide competitive edge and sustainable growth (Power \& Simon, 2004; Moberg, Cutler, Gross \& Speh, 2002; Sezen, 2008; Okongwu, Brulhart \& Moncef, 2015). Depending on the strategic aspect of SCMPs, they would be able to clarify SCMP's twofold goal of improving organizational efficiency and improving the performance of the whole SC (Wong, Tjosvold, Wong \& Liu, 1999). Companies have now recognized that it is not only sufficient to boost its competence, but it is essential, in this dynamic environment, that the whole SC is competitive. It has thus become one of the requirements needed to sustain competitiveness in the global race and to increase benefit to recognize and practice SCM effectively (Tan, Lyman \& Wisner, 2002; Childerhouse \& Towill, 2003).

SCMPs are designed to reduce the expense of the SC and attain a strategic edge for firms. When the corporation understands the value of the SCMPs intending to increase the efficiency of its business and coordinating with SC partners, it will achieve a competitive edge. SCMPs contribute to customer loyalty and increase the efficiency of the business to a high standard (Ou, Liu, Hung \& Yen, 2010). SCMPs enhance internal company success, and the whole SC. SCM aims to integrate internal operations and external connectivity with vendors, consumers and other channel stakeholders closely to remain competitive and achieve sustained development of the profitability (El-Garaihy, 2020). This can be done by building the different SCs efficiently (Li, Ragu-Nathan, Ragu-Nathan \& Subba Rao, 2006). In his study of small and large production companies, Wook Kim (2006) found that productive convergence of small enterprises contributes to sustained performance improvement. In the end, this has a big effect on performance improvement. Once the integration is applied, SCMPs and the competitive edge should be centered. In their analysis, Othman, Sungkar \& Sabri Wan Hussin (2009) stated that successful knowledge exchange is at the heart of the strategic advantages of an organization.

The metrics of success vary following varied industries and various SC objectives. The efficiency of the SCM method is obvious by being experienced a lot by companies of the SCM system to improve their performance (Tripathi \& Gupta, 2019). SCM modifications act as evaluation systems for both intercompany and intra-company operators and are proposed to help find prospects for improving the efficacy and competitiveness of SC. This method directs business systems to meet consumer demands as well as to reach determined goals (Lyons, Mondragon, Piller \& Poler, 2012). Various methods were taken to identify SCM behavior under certain requirements for the evaluation of SC efficiency measurements. Gunasekaran \& Kobu (2007) show that the success assessment is divided according to the various metrics of their financial, final user, internal working practices, and their learning and growth, including the balanced scorecard viewpoint.

Based on our extensive review of the literature published in the field of SC, SCMPs, and SCM performance, which were previously reviewed, it can be observed that there is a gap that exists in studying what are the dimensions that shape SCMPs, and what are the dimensions that help in measuring the performance of the SC, so the current study tries to answer the following important questions:

1. In Saudi industrial organisations, what are the measurements of SCMPs?

2. In Saudi industrial organisations, what are the measurements of the SCM performance?

3. Will the SCMPs and SCM performance measurement scale be established and validated?

Based on what has been presented, in the following parts, those important topics will be presented in the following order: SC management practices (SCMPs), SC management (SCM) Performance Measurement, Research methodology, Data analysis and interpretation, implications, and future research, and finally, conclusion.

\section{SC Management Practices (SCMPs)}

SCMPs can be described as the package of activities carried out by an enterprise to enhance its SCM. Any activity within the SC that enhances the organization's overall success can also be seen as SCMPs. The majority of the scientists examined a 
small range of SCMPs empirically. Donlon (1996) for example has included various activities including: suppliers, outsourcing, cycle time compression, operation continuous flow, and IT. A pilot evaluation for a variety of SCMPs was performed by Tan, Kannan \& Handfield (1998) covering, customership, pricing, and buying. Practices in Tan (2001) include knowledge sharing, content circulation, mass allocation, and policy on postponement. Next year, Tan (2002) examined a new range of supplier assessment practices, covering: supplier and customer management, time-efficiency, geographical proximity, product, and distribution assessment, and exchange of knowledge. (Chin, Rao Tummala, Leung \& Tang, 2004) performed a survey of manufacturing organizations in Hong Kong. The study includes the research of client and supplier partnerships, materials reflow regeneration and operational culture development, implementation of ICT, and definition of performance. Li et al. (2004) analyzed five aspects of SCMPs: consumer interactions, supplier relations, data sharing efficiency, and postponement. Researchers find that SCMPs have a favorable impact on competitive advantage, and business success. Sezen (2008) stressed the following aspects: the convergence of the SC, the sharp share of knowledge on the SC and the nature of the SC. The three SCMPs have little impact on efficiency and flexibility, while the architecture of the SC is the only aspect impacting production performance and resource performance. Srivastava (2006) focused on: SC alliances, SC organization, transport and logistics, network architecture, and the ICT role. Lenny Koh et al (2007) combine SCMPs into two elements: (1) multi-provider outsourcing, (3PL), electronica, multiple suppliers, outsourcing, and (2) strategic cooperation and lean methods (Close partnership with suppliers, SC measurement, close partnership with customers, JIT supply, safety stock keeping, strategic planning, few suppliers).

Customer and provider partnerships, knowledge sharing level and efficiency, postponement, negotiated priorities, agreed on goals and vision, and revenue / risk-sharing were assessed by (Pandiyan Kaliani Sundram, Razak Ibrahim \& Chandran Govindaraju, 2011). In the two dimensions, SCMPs were examined, consumer and supplier relationships and knowledge sharing levels and efficiency, by (Elwan Ibrahim \& Ogunyemi, 2012). Flynn, Huo \& Zhao (2010) analyzed the effect on operational and corporate efficiency of the SC incorporation. They find that internalization and client incorporation correlate favorably with operational efficiency, while internalization correlates only with market performance.

Elmuti (2002) described outsourcing practices as a cost reduction method for logistics, warehousing, human resource management, and IT. SCMPs are classified as asset control, provider management, and customer management by (Udomleartprasert and Jungthirapanich, 2003). As SCMPs, (Chen \& Paulraj, 2004) included environmental volatility, IT, strategic sourcing, infrastructure, and supply structures. As regards strategic partnering with suppliers, knowledge exchanges, customer interactions, the efficiency of information sharing, and postponement, (Li, Xu \& Kumar, 2007) have established five aspects of SCMPs. Chow et al. (2008) have described the SCMPs as SC characteristics, consumer and supplier management and knowledge sharing, convergence, coordination, and pace in their analytical study.

Li, Rao, Ragu-Nathan \& Ragu-Nathan, (2005); Li, Ragu-Nathan, Ragu-Nathan \& Subba Rao, (2006) presented six separate elements of SCMPs, including supplier strategic collaboration, client relationships, knowledge exchange, consistency of information, better internal processes, and deferment. From their point of view, Zhou \& Benton (2007) introduced three SCMPs components: SC planning, (JIT), and supply practices. Lenny Koh et al (2007); Bayraktar et al. (2009), present a set of 12 SCMPs, including close partnerships to suppliers, strong customer partnerships, on-time supplies, and strategic planning, comparative SC measuring, small numbers of suppliers, security stock maintenance, electronic purchases and the presence of a large number of suppliers, the presence of several suppliers and supplier companies, the presence of numerous suppliers, and the company and other companies. With respect to Robb, Xie \& Arthanari (2008), four key components were considered: customer relations, supplier relations, e-commerce, and software used by the organization. In Hsu, Tan, Kannan \& Keong Leong (2009), the practices were: Increasing suppliers, JIT, participation in resource decision-making, proximity to geographical suppliers, formal agreements to share information, improving the integration of activities, searching for new ways to achieve integration, continuing strategic needs in the future, on-time delivery, and reduced response time.

Vendor-managed inventory (VMI), Collaborative planning and forecasting (CPFR), and radio frequency identification (RFID) are some of the SCMPs discussed by Mohd (2007). Supplier strategic relationship, customer relations, degree of information sharing, the efficiency of information sharing, and postponement are the five dimensions of SCMPs defined by (Li, Xu \& Kumar, 2007). SCMPs are characterized as a supplier and consumer management, SC features, communication and speed, knowledge sharing, and integration, according to a study proposed by (Chow et al., 2008). SCMPs may also be classified as spatial and profit margin costing, setup, efficiency indicators, forward order, supply, replenishment frequency, and batch device quantities, (Zairi, 1998). SCMPs are classified by Beamon (1999) into product turnover, profit margin and profit itself, inventory average, and inventory measurement capacity.

SCMPs were evaluated by Chong, Chan, Ooi \& Sim (2011), who looked at provider partnerships, knowledge and IT sharing, client relationships, and preparation. The best SCMPs and their impact on SC results were the subjects of (Anuar \& Mohd Yusuff, 2011). By reviewing previous research, Gharakhani, Mavi \& Hamidi (2012) established twenty-four SCMPs and developed six of them: SC convergence, knowledge exchange, SC features, customer experience management, geographical proximity, and Jit. SC success, product differentiation, time management leadership, postponement, inventory and cost management, communication and exchange of knowledge, buyer-seller partnership, and retail strategy are some of the SCMPs suggested by (Yew Wong, Stentoft Arlbjørn \& Johansen, 2005). SCMPs, according to Mahbubul \& Rafikul (2013), include demand volatility and seasonal drivers. SCMPs may also be divided into different categories, such as spatial and profit margin pricing, setup, efficiency indicators, forward purchase, distribution, renewal pace, and batch device volumes 
(Drohomeretski, Gouvea da Costa, Pinheiro de Lima, \& Wachholtz, 2012). SCMPs are divided into four categories by Morali \& Cory (2013): product turnover, profit margin and profit itself, inventory average, and inventory measurement capacity.

Five SCMPs were proposed by Cook, Heiser \& Sengupta (2011): knowledge sharing, long-term partnerships, advanced forecasting approaches, Internet use, and supply and delivery network systems. SC convergence, knowledge exchange, customer-supplier partnerships, and postponement are four SCMPs proposed by (Lopes de Sousa Jabbour, Gomes Alves Filho, Backx Noronha Viana \& José Chiappetta Jabbour, 2011). SCMPs, according to (Abdallah, Obeidat \& Aqqad, 2014), include SC convergence, knowledge sharing, and SC architecture. SCMPs are a winning formula for many businesses in a variety of sectors (Kayakutlu \& Buyukozkan, 2010; Gorane \& Kant, 2015). To conceptualize SCMPs, Min \& Mentzer (2004) used seven main variables: SC leadership, risk and incentive sharing, agreed vision and priorities, knowledge exchange, longterm partnerships, process alignment, and teamwork.

Based on extensive literature review in the field of SCMPs, twenty constructs have been identified to represent the most frequently used SCMPs in SC literature (Ou, Liu, Hung \& Yen, 2010; Talib \& Rahman, 2010; Talib, Rahman \& Qureshi, 2011; Chong, Chan, Ooi \& Sim, 2011; Anuar \& Mohd Yusuff, 2011; Gharakhani, Mavi \& Hamidi, 2012; Gawankar, Kamble \& Verma, 2013; Jraisat \& Sawalha, 2013; Mohammad Mosadeghrad, 2014; Gorane \& Kant, 2016; Kaliani Sundram, Chandran \& Awais Bhatti, 2016; Gawankar, Kamble \& Raut, 2017; El-Garaihy et al., 2020, El-Garaihy, Badawi, Moawad, \& Azizi, 2020), so it was all relied upon to explore which of these practices Saudi industrial companies adopt to measure SCMPs, and what dimensions these organizations adopt to measure SCM performance. Through the reviews that were made, it became clear that the most frequently used practices in the literature of SCMPs can be listed in strategic partnership of suppliers, customer relations, information sharing, quality of information, postponement, agreed on vision and goals, sharing of risks and rewards, lean manufacturing, TQM, Organizational Culture, Information, and Communication Technology, Benchmarking and Performance Measurement, Agile Manufacturing, Outsourcing, JIT manufacturing, Green SC Management, Reverse Logistics, Vendor managed inventory (VMI), Radio frequency identification (RFID), and SC integration are the twenty practices adopted by this study.

Strategic suppliers' partnership practices (SSPPs): Supplier integration is defined as "a long-term relationship between the organization and its suppliers. It is designed to utilize the strategic and operational capabilities of the participating organizations to help them achieve substantial and sustainable benefits" (Li et al., 2004). The integration of suppliers can be described across a variety of aspects and activities: information sharing, coordination, trust, joint technologies, integrated operations, long-term contracts, providers' assistance in enhancing manufacturing processes, quality improvement promotion, investments in supplier asset, in the development of new products and an increase in supply capability, results of integration in improving decision-making, enhancing knowledge exchange and capacity planning, building learning procedures, and increasing SCM performance. Strategic partnerships with suppliers encourage a long-term relationship with SC stakeholders (Li, Rao, Ragu-Nathan \& Ragu-Nathan, 2005; Qrunfleh, Tarafdar \& Ragu-Nathan, 2012). This strategy improved corporate skills and mutual integration between partners in the supply chain (Wook Kim, 2006; Holt \& Ghobadian, 2009). Efficient partnerships with suppliers often provide shared planning opportunities and collaborative efforts to resolve issues among SC stakeholders (Gunasekaran, Patel \& Tirtiroglu, 2001). Long-term strategic partnerships between suppliers thus allow the company to have a strong, collaborative link for ongoing success.

Customer relationship practices (CRPs): CRPs are practices that the company uses to satisfy all of its specific customer demands, including customer contact management, customer complaints, and customer loyalty improvement (Tan, Kannan \& Handfield, 1998). If you have valuable customer relationships, your company will differ from its competitors (Cox, 2004; Dadzie \& Winston, 2007). The company will then create a positive relationship with customers based on better customer service and loyalty (Elofson \& Robinson, 2007). CRPs are therefore an essential part of improving partnership coordination and cooperation efforts among SC members (Wadhwa, Kanda \& Bhoon, 2006).

Information sharing practices (ISPs): ISPs are described as "the degree to which sensitive and confidential information is transmitted to a single SC partner" (Li et al., 2004). The development of knowledge exchange in the SC has been profoundly influenced by progress in information technology. routine information sharing allows SC parties to operate as one body (Stein \& Sweat, 1998). Information exchange includes various forms related to inventory, personnel, goods, production, delays, and information preparation (Sakka \& Botta-Genoulaz, 2009). It can also include information on quality and distribution, consumer and general industry information, and design information. The knowledge exchange must be adequate, exact, reliable, and timely to produce better outcomes (Li et al., 2004). The exchange of information influences customer response efficiency, lower prices, better levels of service, and lower level of sophistication (Zhao, Xie \& Zhang, 2002). In addition, the $\mathrm{SC}$ is accelerated and made easy to make accurate decisions through efficient and reliable information dissemination and exchange. This can be seen as a strategic advantage (Moberg, Cutler, Gross \& Speh, 2002).

Information quality practices (IQPs): Information Quality covers all aspects in terms of precision, speed, adequacy, and reliability of effective and reliable information management and communication (Li, Ragu-Nathan, Ragu-Nathan \& Subba Rao, 2006). Multiple studies have presented enough evidence that careful control of knowledge content can be a strategic advantage inside and across an enterprise (Wook Kim, 2006; Lenny Koh et al., 2007). Forslund \& Jonsson (2007) pointed out that knowledge sharing and its practices among SC partners will allow their SC activities to be well coordinated. Organizations should also consider IQPs as an inclusive strategic instrument to ensuring that the knowledge exchange is not 
distorted or manipulated (Gustavsson, 2008). This will also not only strengthen the decision-making but also contribute to the achievement of the best SC operating solution, which supports the strategic benefit of the company.

Postponement practices (PSTPs): The postponement applies here to the activities which are requested to suspend such operations at a later date or at a time in the SC, to provide the commodity with added value or to increase customer loyalty (Beamon, 1998). To be able to customize the company more flexibly and technically, it has to be streamlined and receptive to consumers to satisfy changing consumer needs (Yang, Yang \& Wijngaard, 2007). In summary, the performance of postponement processes relies heavily on the potential to be more organized in both operating departments internally and externally by business partners (Cvsa \& Gilbert, 2002). In the longer term, postponement allows SC organisations to decrease inventory stocks, increasing in turn, the efficiency of SC (Yang, Yang \& Wijngaard, 2007).

Agreed vision and goals practices (AVGPs): In a dynamic world market and the strategic links and collaboration between partners, the performance of commercial activities significantly depends on (Boddy, Macbeth \& Wagner, 2000). The sharing of knowledge, trust, and engagement between partners is one of the most critical ways to establish an enterprise philosophy to achieve this sustainable partnership between the partners (Nasurdin, Hemdi, \& Guat, 2008). To ensure the successful exchange of intelligence, confidence, and engagement between the SC commercial partners, organizations should devise an agreed vision and establish shared objectives among the SC participants (Spekman, Kamauff \& Myhr, 1998). This would ultimately ensure that SCMPs succeed in improving their SC results and have a positive effect on their competitive edge.

Risk and reward sharing practices (RRSPS): The increased competitiveness of the world economy and increasing sophistication of the SC have made risk and reward management increasingly significant (Kleindorfer \& Van Wassenhove, 2004). To address strategically the current domestic and global competitive market, efficient practices for shared hazards and incentives among manufacturers, producers, distributors, and customers should be given serious consideration (Min \& Mentzer, 2001). Risk and reward-sharing activities ensure that contacts between members of the SC are established and thus encourage close cooperation among business partners. This encourages the company and its members to reduce the amount of confusion over technologies, consumers, or market-oriented interventions in business processes (Ritchie \& Brindley, 2007).

Lean manufacturing practices (LMPs): Lean means waste-free production. A waste is completely essential for the manufacturing and providing manufacturers and consumers with premium goods at the lowest possible expense, except for the minimal quantity of machinery, components, replacement parts, and working time. The lean strategy is aimed at eliminating waste consistently in the value stream. The waste principle covers both faulty businesses/activities and not just faulty goods. Waste may be classified into eight categories: movement, maintenance, correction, overtreatment, overproduction, shipping, stockpiling, and expertise. The philosophy of Lean yields greater efficiency, competitiveness, and response from customers. Empirical research has shown that the Lean Strategy effect increases the competitive advantage of an enterprise (Doolen \& Hacker, 2005). The impact of flexibility can be claimed not only in production but also in the whole of SC as an essential technique. In most industries, Lean gained traction worldwide (Garza-Reyes, et al.,, 2012). Today this approach is regarded as the leading modern model of production and improves organizations' competitive edge (Hines, Holweg \& Rich, 2004). In academic literature, the idea of Lean SCs has been widely explored (Chen, Rungtusanatham, Goldstein \& Koerner, 2013; Qrunfleh \& Tarafdar, 2013). These studies show, in most cases, that lean concepts and methods help good SCM.

Total Quality Management Practices (TQMPs): TQM is a philosophy of management that underlines the need to respond properly to the needs of internal and external customers and to carry out tasks and processes (Al-khalifa \& Aspinwall, 2000). The authors' consensus on what constitutes TQM was stressed (Jabnoun, 2002). However, in the scholarly literature, the most mentioned elements in TQM are benchmarking, provider ties, continued improvement, the loyalty of customers, empowerment, and top management accountability (Garza-Reyes, et al., 2011). Although the outcomes achieved by applying TQM to organizational success have been controversial (Mohammad Mosadeghrad, 2014), quality management is deemed one of the key components of SCMPs (Jraisat \& Sawalha, 2013).

Organizational culture practices (OCPs): Since the 1980s, research into corporate culture has become a priority. Culture is described by Barney (1986) as the "complex collection of principles, attitudes, assumptions and symbols that form the way an organization runs its business." He argues that culture can have a strategic edge and contribute to enhance and improve results. There are two dimensions of organizational culture, Its first factor is the corporate interest. It is related to organisations, which are focused on the internal aspect (well-being and development of people in the organization). The second factor concerns SC partners' mutual links (Quinn \& Rohrbaugh, 1983).

Information and communication technology practices (ICTPS): ICT is described as the framework used to electronically organize and incorporate data flows through the trade SC partners network and in both directions. To facilitate fast access to information, ICT provides reliable, and productive business transactions, enabling improved service to customers, minimizing paperwork, better connectivity, increased efficiency and saving time. In SCM's growth, technology is a major contributor. Before that, organisations had trouble accessing information without internet apps so they couldn't collect or transmit information, alerts, responses, or other relevant information promptly (Power \& Simon, 2004). Organizations will also regularly interact with each other within the SC owing to ICT progress. The architecture of SCM includes the 
coordination of SC members' logistics and production activities. This kind of collaboration with ICT is possible in particular as these innovations cover the conventional frontiers of SC organizations.

Benchmarking and performance measurement practices (BPMPs): The principle of benchmarking has gained in popularity in recent years and benchmarking is the alignment of corporate processes or results of a company with that of a group of like businesses. Performance assessment is a popular method used internationally to enhance market entities' performance and competitive advantage (Gosselin, 2005). The biggest challenge with every organisation is the performance assessment. For example, organizational performance assessment promotes quality development, enhances and reinforces SC activity, and provides the knowledge necessary for feedback management, diagnosis, and organizational problem-solving. Neely, Gregory \& Platts (1995) have characterized performance assessment as a process to quantify work quality and effectiveness. Effectiveness tests to the degree the needs of the customers are satisfied, while efficiency measures how economically the resources of an enterprise are used to provide a prescribed level of customer satisfaction. Neely, Gregory \& Platts (1995) has defined a range of performance assessment methods, including Balanced Scorecards (Kaplan \& Norton, 1992); and Bottomline Benchmarking Matrix (Keegan, Eiler \& Jones, 1989); Performance Evaluation Framework (Dixon, Nanni, \& Vollmann, 1990); and Measurement system model criteria.

Agile manufacturing practices (AMPs): Until the consumer is pleased, AMPs should be counted. Agile production is an entrepreneurial philosophy underlying agile production processes. Flexibility means that the consumer can easily switch to a product or size combination flexibility (Christopher \& Towill, 2000). The capacity to quickly turn the production line from product to product is essential for greater flexibility, less lead time, and flexible production (Mileham, Culley, Owen \& McIntosh, 1999). More production flexibility means greater flexibility to meet consumer demands, adapt to competitive conditions and market proximity (Slack, 2005). The flexibility of the products available enhances the potential of the group to react rapidly and to produce good results through the provision of a wide variety of products (Zhang, Vonderembse \& Cao, 2006). The five kinds of versatility that Slack (2005) defined are New product flexibility, product mix elasticity, quality elasticity, size flexibility, and delivery flexibility. A conceptual model for the flexibility of SC has been developed by Lummus, Duclos, \& Vokurka (2003), covering operating processes, activities in manufacturing, supply network, organizational architecture, and personnel information system.

Outsourcing practices (OUTPs): Outsourcing means the utilization of services outside the organisation, which the organisation's activities normally manage internally. Effective outsourcing is a valuable strategy for companies to benefit competitively from others and helps them to concentrate on their core competencies (Wei Khong, 2005). Outsourcing covers many areas such as architecture, engineering, marketing, delivery, IT systems, cleaning, catering, and safety (McIvor, 2000). Outsourcing allows funds to be made available and prices to be reduced in the current fiscal year. Outsourcing reports generate substantial cost savings and enhance operating stability (Hendry, 1995).

Just In Time manufacturing practices (JITPs): The manufacturing theory of JIT requires the absolute minimum inventory level to be achieved by fulfilling customer orders, except for one unit, while improving efficiency (Savsar, 1997). In addition to a payment strategy, JIT includes the implementation of the cloud production strategy and uses Kanban cards to the same end. The introduction of JIT will bring major benefits to manufacturers, such as lower stock prices, better response levels, and improved relationships with suppliers (Ismail Salaheldin, 2005). The fact that this factor is an integral part of the structure and construction of SCMPs has led to building the organization's competitive potential.

Green SC Management practices (GSCMPS): GSCMPs are described as the mechanism by which they use inputs that are environmentally friendly and turn them into outputs that can be reclaimed and reused at the end of their life cycle and create a sustainable SC. Sustainable development means development that meets the needs of today without jeopardizing future generations' potential. Sustainability, in short, encompasses three main aspects: economic, environmental, and social responsibility. Organizations that embody efficiency in their strategies have measures in place to enhance the success of the organisation in all three ways. For GSCM to succeed, organisations must transform their form from conventional technology to modern technology (Luthra, Kumar, Kumar \& Haleem, 2011). During this transition, companies are still resistant to technical progress. This particularly applies as improvements are made to the fundamental characteristics of organisations, including corporate objectives, structures of authority, key technologies, business strategies, and business strategy.

Reverse logistics practices (RLPs): RL is all methods associated with the reuse of materials and objects. It is the method that involves preparing, executing, and monitoring the productive flow of raw material costs from consumer to point of origin to recover value or proper disposal, inventory during manufacturing, finished products, and related details (Guide, Jayaraman, Srivastava \& Benton, 2000). A lack of awareness of the usefulness of RL is a huge hurdle. The biggest problem of recycling also costs considerations. To incorporate RL, organizations need the allocation of funding and other tools. ICT still needs more funding, but, without it, income goods and commodity recovery in the current market cannot be tracked or monitored. Training RL-related workers is therefore very critical to handle them effectively so that RL eventually becomes profitable.

Vendor managed inventory practices (VMIPs): To decide on the appropriate inventory levels for each commodity, VMI is the appropriate solution for the customer-supplier partnership. The retailer supervises the buyer's stock and occasional replenishment according to the sales forecast (Danese, 2006). VMI offers both the customer and the seller a win-win condition (Kumar \& Kumar, 2003). The retailer would provide details on the inventory, expected demand, marketing efforts, and the costs associated with the commodity from the purchaser so that they can handle the inventory (Barratt, 2004). This allows 
detail to be made available to the retailer sooner and reduces lead times. Precise and timely information on orders must be communicated between the selling and procurement roles of the customer and the schedule of the supplier. Organizations also refuse to share their vendors with their sensitive data and documents.

Radio frequency identification practices (RFIDPs): RFID is an alternative to the gradually introduced and implemented barcode reconnaissance systems for a broad range of uses (Lee \& Park, 2008), including production, shipping, distribution, stock of warehouses, advertising, marketing, and service customers (Park, Shin, Chang \& Park, 2010). RFID is called the radio transmitted signaling wireless technology. In the first stage of production to accompany the product from the outset of the SC to the retail stage, and finally, in the hands of customers, the RFID tag is connected with the product. Consumers can use the private label for guaranteed details after purchasing in retail activities (Attaran, 2007). RFID technology has many benefits for manufacturers, retailers, and customers, including increased inventory tracking accuracy, better order visualization and inventory, lower distribution costs, improved customer experience, security, and business-process productivity (Lenny Koh et al., 2007). Extra profits include automatic scanning, and reduced employment due to enhanced automation, increased visibility, improved asset tracking and inventory management, traceability of items, traceable guarantees and targeted recalls of products, improved reliability, quality control and regulations, improved resource use, and product retention security (Michael \& McCathie, 2005).

SC integration practices (SCIPs): By combining their contacts, activities, jobs, activities, and sites, SCI links the organisation to clients, vendors, and other channel operators (Wook Kim \& Narasimhan, 2002; Naslund \& Hulthen, 2012). SCI comprises two phases: internal functional integration and external partnership integration. Internal integration describes tight links between diverse roles such as shipment and inventory or raw materials procurement and management (Trkman \& Groznik, 2006). External integration has two objectives: to promote the integration of vendors, distributors, and consumers of physical delivery flow, to reverse synchronization of IT, and to include consumer, vendor, and supplier flow data (Schoenherra \& Swink, 2012; El-Garaihy, Badawi, Moawad, \& Azizi, 2020).

\section{SC Management Performance Measurement}

SC scientists have established a large number of SCMPs that achieve superior efficiency (Chen \& Paulraj, 2004). Though analysis studies vary in variables and methodology preferences, empirical data converges when reporting substantial positions between discrete SCMPs and performance (Paulraj, Chen \& Lado, 2012).

The vision of designing output measurement metrics for SCM performance is not evident for most firms (Shepherd \& Günter, 2006). In their analysis (Sukati, Hamid, Baharun \& Yusoff, 2012), three different types of performance measurements, i.e., measuring resources, the extent to which resources are obtained successfully from sources, measuring outputs, as effective to provide value to the customer, and flexibility should be taken into consideration in the measuring of the performance of $\mathrm{SC}$, how flexible the system is in dealing with external uncertainty. They stressed that the SC output of industrial companies is of equal importance for both of these groups. Despite the tremendous amount of knowledge available on the various output measurement approaches of the SC, researchers continue to stress the need for continuous studies in this field because of the lack of a quantitative measure of the SC for all contexts (Qrunfl eh \& Tarafdar, 2012; Bhagwat \& Sharma, 2007).

Study into various facets of SCM is replete with previous literature; however, data assessing measurement methods for SCM's success are lacking. The dearth of metrics for SC is tangible, after a rigorous literature review. As an approach for maximizing $\mathrm{SC}$ and increasing SC competition, a performance assessment framework is essential. Performance measurement is intended to promote target design, identify next actions, and perform evaluations on an organizational, institutional, and strategic basis. It is noted that the majority of companies are still functionally or informally focusing on their business success and measuring their SC results with financially focused criteria (Hervani, Helms \& Sarkis, 2005). Initially, it is a realistic solution, instead of intending to apply firm evaluation of results, including consumers and vendors of a business, to assess its performance at the SC. The transformation from cost-oriented strategies to personalizations and value-added strategies reflects the effects of increased market demand and the volatile enterprise environment, which have contributed to the transition from cost-oriented strategies to value-added strategies. SCs and the function of human bodies have changed and improvements in performance evaluation processes have increased (Leończuk, Ryciuk, Szymczak \& Nazarko, 2019).

The present study will rely entirely on the simplified scale proposed by (El-Garaihy, 2021) as its output is measured in SC which offers a collaborative SC structure by combining two approaches, i.e., decision-making levels and SC operational referrals (SCOR). It developed an innovative model for measuring the output of the SC with a total of 31 subcomponents, comprising 4 variables (customer, reliability, versatility, and product). To the functionality characterizing SC efficiency, the framework provides horizontal and vertical linkages (SCOR) and progressive decisions. The decision-makers are willing to take political, logistical, and organizational decisions through this mechanism. It represents the reliability, authenticity, and implementation of success metrics in many SCs. It also enhances coordination with the provincial group and ensures a preventive maintenance plan.

4. Research methodology

\subsection{Design, sample, and bias of the study}

This thesis examined and carried out a cross-sectional method in Saudi Arabia. SC administrators and experts from Saudi industry firms were included in the report. In the last quarter of 2020, some 600 questionnaires were distributed, followed up 
in the first quarter of 2021, but after review of the results, the sample finalized was 351 and the response rate was $58,5 \%$. On that basis, it can be said that the sample dimensions of the analysis are greater than the minimum sample size, as confirmed by (Hair, Ringle \& Sarstedt, 2011), based on ten times the basic method. Table 1 summarizes the demographic outlines of the respondents and their companies.

Table 1

Respondents' demographic profiles

\begin{tabular}{|c|c|c|}
\hline Item description & Frequency & $(\%)$ \\
\hline \multicolumn{3}{|l|}{ Business type } \\
\hline Chemical, fabric, plastic & 42 & 12 \\
\hline Pharmaceutical & 55 & 15.7 \\
\hline Fabric, leather, fur, shoes & 33 & 9.4 \\
\hline Paper, pulp & 19 & 5.4 \\
\hline Metal material & 32 & 9.1 \\
\hline Assembled metal products & 16 & 4.6 \\
\hline Electronics and communication equipment & 53 & 15.0 \\
\hline Electric, mechanical, appliance & 35 & 10.0 \\
\hline Automobile and automotive parts & 24 & 6.8 \\
\hline Ship machinery equipment, precision machinery & 20 & 5.7 \\
\hline Others & 22 & 6.3 \\
\hline Total & 351 & 100.0 \\
\hline \multicolumn{3}{|l|}{ Participants position in the organization } \\
\hline Top management (i.e., President, CEO, Vice President) & 34 & 9.7 \\
\hline Middle Management (i.e., Director, Senior Manager, Manager) & 286 & 81.5 \\
\hline Supervisory level (i.e., senior officer, officer, coordinator) & 16 & 4.5 \\
\hline Non-managerial (i.e., accountant, assistant, specialist, etc.) & 15 & 4.3 \\
\hline Total & 351 & 100.0 \\
\hline \multicolumn{3}{|l|}{ Location of responding firms in Saudi Arabia } \\
\hline Eastern Province & 78 & 22.2 \\
\hline Central Province & 174 & 49.6 \\
\hline Western Province & 51 & 14.5 \\
\hline Northern Province & 36 & 10.3 \\
\hline Southern Province & 12 & 3.4 \\
\hline Total & 351 & 100.0 \\
\hline \multicolumn{3}{|l|}{ Size of firms (Number of employees) } \\
\hline $51-100$ & 120 & 34.2 \\
\hline $101-300$ & 107 & 30.5 \\
\hline $301-500$ & 46 & 13.1 \\
\hline $501-5000$ & 71 & 20.2 \\
\hline More than 5000 & 7 & 2.0 \\
\hline Total & 351 & 100.0 \\
\hline \multicolumn{3}{|l|}{ Number of years in business } \\
\hline $1-5$ & 17 & 4.8 \\
\hline $6-10$ & 58 & 16.5 \\
\hline $11-20$ & 105 & 29.9 \\
\hline 21 or more & 171 & 48.8 \\
\hline Total & 351 & 100.0 \\
\hline \multicolumn{3}{|l|}{ Legal status and ownership } \\
\hline Government & 16 & 4.6 \\
\hline Semi-government & 14 & 4.0 \\
\hline Private company & 289 & 82.3 \\
\hline $\mathrm{MNC}$ & 32 & 9.1 \\
\hline Total & 351 & 100.0 \\
\hline
\end{tabular}

Source: Authors' preparation

The table states that eleven separate areas of operation are covered in the work covered by the survey. The area of pharmaceuticals represents the largest sample of $15.7 \%$; the electronics and communication devices sector is $15 \%$, followed by the chemical and rubber sectors by $12 \%$, and the manufactured metal products represent $4.6 \%$, the lowest percentage of the businesses in the sample. In addition, $81.5 \%$ of the sample responses are middle managers and $9.7 \%$ are in senior roles, while the rest are subordinates or non-managers $(8.8$ percent).

To counteract the bias of the sensible approach, what was said in (MacKenzie \& Podsakoff, 2012) is methodological and implemented during the cited study in particular in the formulation of the questionnaire and the administration of the 
interviewee phases. As the respondents were not reactionary at the time (Saeed, Malhotra \& Abdinnour, 2019), the survey was divided into two categories to list all first and delayed responders. The sample was classified into three parts. T-tests examined the averages of the classes and the findings found at level .05 were negligible. It shows the lack of prejudice with regard to the questionnaire, based on analysis.

\subsection{Tool for Data Collection}

For data gathering a questionnaire has been used and divided into three sections: one contains questions relevant to the population details of respondents, while the second included the elements for evaluating SMCPs derived from previous research (20 buildings with 160 entities, see Appendix A), and the last consisted of measures to evaluate the performance of SCM (4 constructs with total 31 elements, see Appendix A). Certain elements have been derived from detailed analyses of SC, SCMPs, and SCM performance tests previously reviewed; These elements were collected (For information on the calculation components from previous research, please see Appendix A.).

The Likert scale of five points, starting from 5, assessed all the scale items: 1: so much disagreement to 5: Strongly agree. Before the data were collected, business analysts and researchers checked the feasibility of the questionnaire. This questionnaire was originally described to SCM academics who worked at Imam Abdul Rahman bin Faisal University, Dammam, Saudi Arabia. After 25 industrial experts from the Eastern Province of Saudi Arabia had reviewed the questionnaire and their recommendations were combined to ensure the validity of face and content.

Almost all were agreed that the practice of the inventory management vendor (VMI) and the Radio frequency identification (RFID) was not conducted in Saudi manufacturing organisations. There was a clear consensus among all the parties. Rather, others stressed that very few multinational organizations adopted these procedures, so that the implications of both practices did not undermine the findings that can be gathered during the study, but that they recommended that those practices should be deleted from the questionnaire before being sent to respondents. We deleted the 2 practices, based on the methodology, so that there are only 18 SCMPs structures in the questionnaire and 4 SCM performance constructs. The remaining remarks concerned the length and multitude of variables in the questionnaire.

The survey was again sent to the same experts. They said that few issues must be rephrased to make them easy to comprehend. The related questions have also been rephrased. The whole experiment eventually allowed us to reach the questionnaire's validity. The list of SCMPs (160 items) and SCM performance (31 items) metrics are presented in Appendix A. These elements helped us to develop a tentative questionnaire based on the research objective of this paper. Appendix B indicates the elements of each consideration posed to respondents in the Kingdom of Saudi Arabia industrial sector firms (SCMPs list 147 items) and SCM performance metrics (31 items) after the removal of the VMI and RFID practices. The final calculation elements of the model obtained after all statistical procedures are seen in Appendixes.

\subsection{Analysis of data}

To identify missing data and to detect multivariate and univariate contours, the results obtained by the questionnaire were verified with the SPSS program. Following the data review in the previous step, the Smart PLS 3.2.4 program was used to model the least square component structural equation.

The key issue in this study is the development and validation of an SCMPs scale in Saudi industries and this study aims at conceptualizing, developing, and validating a scale for the of SCMPs practices adopted by Saudi industrial organizations as well as the assessment of their performance.

\subsection{Confidence of the survey instrument}

A pilot survey was conducted among 25 workers employed in acquisition, manufacture and procedures, logistics, and delivery through various organizations to detect the reliability of the measuring instrument. The instrument's magnitude reliability was monitored using the alpha coefficient of Cronbach in respect of the SCMPs and SCM performance variables. The measure of Cronbach's alpha coefficient of the measure is shown to be accurate if it is much higher than 0.700 and the minimum suitable is 0.600 (Hair, Black, Babin, Anderson \& Tatham, 2009). SCMPs scale and SCM performance of the coefficient alpha of Cronbach was simultaneously 0.912 and 0.929 . In accordance with item-to-all correlations, however, those elements had low correlations had been removed (23 items), thus, 124 elements of the SCMPs were kept on the scale, and SCM performance elements remained the same as 31 elements, while the rest of the elements (124 of SCMPs 31 of SCM performance) had highly adjusted item-to-all correlations indicating that presence of high internal consistency.

\subsection{Tests for any differences in sample results}

The non-response bias was evaluated with the t-test of early and late respondents, assuming that the viewpoints of the late respondents reflect the views of the non-respondents (Krause, Scannell \& Calantone, 2000). The respondents were split into two groups: 247 answers obtained at the start of the collection process and 104 replies received at the end of the data collection phase. In all individual issues, A T-test was conducted between early respondents with 247 answers and 104 late respondents who revealed no substantial gaps between the two categories. This shows that the results are largely free of non-response. As the study depended on single respondents for a final report, it was necessary to assess the potential for traditional method bias in influencing the findings (Podsakoff, MacKenzie, Lee \& Podsakoff, 2003). In one-factor tests, Harman finds that a 
single factor that accounts for 50 percent of the variance in the data set either for SCMPs or for SCM performance, does not show a single factor in the non-rotated factor solution. The unifactor test of Harman was further applied separately with confirmatory factor analysis in the SCMPs and SCM performance. Test indices of 124 SCMPs objects are: $\chi 2=1586,432$, $\mathrm{df}=417, \mathrm{CFI}=0,676, \mathrm{NFI}=0,643, \mathrm{RMSEA}=0,117$ when taken as single-factor models. Additional research indexes of 31 SC products are: $\chi 2=1989.514, \mathrm{df}=339, \mathrm{CFI}=0.656, \mathrm{CFI}=0.617, \mathrm{RMSEA}=0.128$ through treatment on one-factor models. The findings above show that the traditional process prejudice in this analysis is not a big problem.

\section{Analysis and interpretation of data:}

The data reviews provide an outline of the descriptive results and the SCMPs and SCM Performance Confirmatory Factor Analysis.

\subsection{Statistics of description}

The answer to the individual things of the SCMPs and SCM performance was asked to be indicated by the respondents. The answers to 124 SCMPs variables and 31 SCM performance variables are given to the lowest grade, highest grade, the mean and standard deviation in Appendix C. Reliability of the scale was again tested with the alpha coefficient of Cronbach. The Cronbach Alpha Coefficient composed of 124 SCMPs variables was 0,921 for this analysis with highly corrected item-tototal correlations. Additional Cronbach Alpha Coefficient was calculated to be 0.919 for a measure composed of $31 \mathrm{SCM}$ variables.

\subsection{Confirmatory factor analysis (CFA)}

A review of the literature previously conducted enabled us to find out SCMP's buildings, and SCM performance. Sections 2 reveals that SCMPs consist of 20 constructs namely strategic partnership of suppliers, customer relationship, information sharing, information quality, postponement, agreed vision and goals, sharing of risks and rewards, lean manufacturing, TQM, Organizational Culture, Information, and Communication Technology, Benchmarking and Performance Measurement, Agile Manufacturing, Outsourcing, JIT manufacturing, Green SC Management, Reverse Logistics, Vendor managed inventory (VMI), Radio frequency identification (RFID), and SC integration (lately, after the presentation to the experts, both of VMI and RFID were excluded). The specific elements of these structures were described earlier and presented in Appendix A. Further section 3 demonstrates that SCM performance has four constructs namely Flexibility Perspective (FLP), Efficiency Perspective (EFP), Customer's Perspective (CSP), Product Innovation Perspective (PIP). The items of such structures were previously identified and seen in Appendix A. This disclosure has led us to explicitly apply the CFA instead of submitting the objects of the SCMPs and SCM performance for an investigation of exploratory factor (EFA).

The content validity of the buildings was assessed before implementing the CFA on SCMP items and SCM results. The validity of the content indicates if the instrument includes measuring elements covering any relevant research issue (Nunnally, 1978). Its assessment is mostly a fair method of judgment. When constructing the survey instrument, the content validity of the tool was achieved. This was done by a comprehensive literature review supplemented by in-depth interviews with expert opinions. In relation to quality, coverage, consistency, ambiguity, and format the experts were asked to review the questionnaire. This led to small improvements in the sentence a few questions to overcome uncertainty and ensure that the respondents will understand easily. This method led to the authenticity of the material of the survey tool. To assess the unidimensionality, consistency, validity convergent to the criteria, and validity of the instrument of the SCMPs as well as SCM performance, CFA was subsequently carried out.

\subsubsection{Unidimensionality}

The definition of unidimensionality means that the elements under consideration measure one theoretical structure, rather than more than one (Gerbing \& Anderson, 1988). Two separate measurement scales for SCMPs and SCM performance have been used. By carrying out the CFA independently, the two components became unidimensional. The number of SCMPs elements was reduced from 124 to 84, thus excluding four of the 18 structures representing SCMPs, the four were JIT manufacturing, postponement, agreed on vision and goals as well as sharing risk and reward. In addition to deleting those four previous dimensions, some elements were excluded from other dimensions due to their weak link with their dimensions, which led to the reduction of SCMPs elements to be 84 elements only. The measuring model was successful for almost all fitness indices. GOF measurements of the SCMPs measuring model are: $\chi^{2}=271.107, \mathrm{df}=149, \mathrm{p}=0.00, \chi^{2} / \mathrm{df}=1.697$, $\mathrm{RMR}=0.048, \mathrm{GFI}=0.907, \mathrm{AGFI}=0.876, \mathrm{NFI}=0.912, \mathrm{TLI}=0.956, \mathrm{CFI}=0.963, \mathrm{RMSEA}=0.054$. The values above show that almost all GOF indexes meet the threshold value (Hair, Black, Babin, Anderson \& Tatham, 2009). Similarly, on SCM performance pieces, CFA has not reduced the number of 31 SCM performance components. GOF metrics of the SCM model have shown to be: $\chi^{2}=311.118, \mathrm{df}=144, \mathrm{p}=0.00, \chi^{2} / \mathrm{df}=2.116, \mathrm{RMR}=0.058, \mathrm{GFI}=0.871, \mathrm{AGFI}=0.842$, $\mathrm{NFI}=0.910$, TLI $=0.931, \mathrm{CFI}=0.948, \mathrm{RMSEA}=0.069$. This model shows that nearly all GOF indexes are fairly well adapted. The findings of the 18 measuring simulations show that all dimensions are uniform.

The CFA on all 18 was also detected by a composite meter's model that combines the scales of SCMPs and SCM performance (14 of SCMPs and 4 of SCM performance constructs simultaneously). The composite measuring model GOF indices are as 
follows: $\chi^{2}=1297.102 \mathrm{df}=699, \mathrm{p}=0.00, \quad \chi^{2} / \mathrm{df}=2.004, \quad \mathrm{RMR}=0.064, \quad \mathrm{GFI}=0.819, \quad \mathrm{AGFI}=0.769, \quad \mathrm{NFI}=0.829$, $\mathrm{TLI}=0.889, \mathrm{CFI}=0.911, \mathrm{RMSEA}=0.060$. Standard GOF cut-off conditions appear overly strict. In standard fitness indices such as GFI or TLI, more liberal cut-off values can be used, considering considerations like model complexity, the number of variables found, and sample dimensions. In the existing literature a comparable finding was published (Vachon \& Klassen, 2006, Zhu, Sarkis \& Lai, 2008, Singh, Power \& Chuong, 2011). The results show fairly well aligned with the indicators above. The results of this composite measuring model were used to determine the reliability of the construction and all other validity tests.

\subsubsection{Reliability}

Two reliability figures were calculated in the present analysis. The alpha coefficient of Cronbach and the reliability coefficient for the structure (Hair, Black, Babin, Anderson \& Tatham, 2009). The threshold for a scale to be deemed accurate has been stated earlier. Even the scale is called accurate if the value of the building reliability coefficient proves to be 0.7 or higher (Hair, Black, Babin, Anderson \& Tatham, 2009). The reliability estimation is considered a composite reliability metric. The compound reliability measurement calculated values are very near to Cronbach's $\alpha$ values as shown in table 2 . All coefficients are seen to be higher than a predefined threshold of 0.7 , which shows that all constructs are reliable.

Table 2

Convergent validity and reliability assessment of SCMPs and SCM performance constructions

\begin{tabular}{|c|c|c|c|c|c|}
\hline Construct & $\begin{array}{l}\text { Number of } \\
\text { items }\end{array}$ & $\begin{array}{l}\text { Alpha (ó) } \\
\text { Reliability }\end{array}$ & $\begin{array}{l}\text { Construct } \\
\text { Reliability }\end{array}$ & NFI & NNFI \\
\hline Strategic Partnership of Suppliers (SPS) & 7 & 0.882 & 0.891 & 0.922 & 0.977 \\
\hline Customer Relationships (CR) & 5 & 0.801 & 0.803 & 0.963 & 0.941 \\
\hline Information Sharing (IS) & 5 & 0.740 & 0.748 & 0.954 & 0.952 \\
\hline Information Quality (IQ) & 5 & 0.824 & 0.843 & 0.964 & 0.939 \\
\hline Lean Manufacturing (LM) & 6 & 0.849 & 0.859 & 0.964 & 0.940 \\
\hline Total Quality Management (TQM) & 11 & 0.898 & 0.902 & 0.959 & 0.938 \\
\hline Organizational Culture (OC) & 5 & 0.889 & 0.903 & 0.971 & 0.944 \\
\hline Information and Communication Technology (ICT) & 6 & 0.823 & 0.866 & 0.949 & 0.936 \\
\hline Benchmarking and Performance Measurement (BPM) & 6 & 0.811 & 0.823 & 0.957 & 0.931 \\
\hline Agile Manufacturing (AM) & 4 & 0.831 & 0.838 & 0.943 & 0.929 \\
\hline Outsourcing (OUT) & 5 & 0.829 & 0.841 & 0.958 & 0.938 \\
\hline Green SC Management (GSCM) & 5 & 0.854 & 0.857 & 0.954 & 0.936 \\
\hline Reverse Logistics (RL) & 6 & 0.903 & 0.899 & 0.949 & 0.937 \\
\hline SC Integration (SCI) & 8 & 0.895 & 0.900 & 0.965 & 0.942 \\
\hline Flexibility Perspective (FLP) & 9 & 0.830 & 0.863 & 0.941 & 0.937 \\
\hline Efficiency Perspective (EFP) & 8 & 0.815 & 0.821 & 0.946 & 0.928 \\
\hline Customer's Perspective (CSP) & 7 & 0.836 & 0.835 & 0.937 & 0.923 \\
\hline Product Innovation Perspective (PIP) & 7 & 0.818 & 0.833 & 0.958 & 0.942 \\
\hline
\end{tabular}

Source: Authors' preparation

\subsubsection{Convergent validity}

A high proportion of the variance common to the indicator variables in a certain structure is associated with convergent validity. It was assessed using three different techniques. The first is to examine the estimated factor loads of artifacts in the final CFA model (Anderson \& Gerbing, 1988). Standard loads were found to be above 0.5 and statistically significant (p $<0.001$ ) for all materials. These variations range from 0.567 to 0.929 , which suggests that there is a very wide variation in any single thing. The second method involves an assessment of the convergent validity of each independent element using two GOF indexes: (NFI) and (NNFI) (Ahire, Golhar \& Waller, 1996).

Table 3

Convergent, discrimination in the field of construction SCMPs and SCM performance nomological effects of validity

\begin{tabular}{|c|c|c|c|c|c|c|c|c|c|c|c|c|c|c|c|c|c|c|}
\hline Construct & SPS & CR & IS & IQ & LM & TQM & $\mathrm{OC}$ & ICT & BPM & AM & OUT & GSCM & RL & $\mathrm{SCI}$ & FLP & EFP & CSP & PIP \\
\hline SPS & 0.737 & & & & & & & & & & & & & & & & & \\
\hline $\mathrm{CR}$ & 0.726 & 0.742 & & & & & & & & & & & & & & & & \\
\hline IS & 0.719 & 0.741 & 0.767 & & & & & & & & & & & & & & & \\
\hline IQ & 0.772 & 0.688 & 0.694 & 0.785 & & & & & & & & & & & & & & \\
\hline LM & 0.601 & 0.512 & 0.467 & 0.567 & 0.820 & & & & & & & & & & & & & \\
\hline TQM & 0.649 & 0.636 & 0.641 & 0.540 & 0.473 & 0.806 & & & & & & & & & & & & \\
\hline $\mathrm{OC}$ & 0.501 & 0.517 & 0.435 & 0.498 & 0.455 & 0.604 & 0.825 & & & & & & & & & & & \\
\hline ICT & 0.499 & 0.524 & 0.513 & 0.400 & 0.432 & 0.750 & 0.496 & 0.829 & & & & & & & & & & \\
\hline BPM & 0.481 & 0.567 & 0.441 & 0.531 & 0.399 & 0.532 & 0.716 & 0.472 & 0.814 & & & & & & & & & \\
\hline AM & 0.583 & 0.491 & 0.437 & 0.502 & 0.685 & 0.615 & 0.727 & 0.522 & 0.678 & 0.809 & & & & & & & & \\
\hline OUT & 0.503 & 0.519 & 0.438 & 0.499 & 0.458 & 0.606 & 0.504 & 0.518 & 0.438 & 0.503 & 0.789 & & & & & & & \\
\hline GSCM & 0.504 & 0.528 & 0.517 & 0.404 & 0.472 & 0.754 & 0.507 & 0.529 & 0.519 & 0.419 & 0.543 & 0.821 & & & & & & \\
\hline $\mathrm{RL}$ & 0.486 & 0.573 & 0.447 & 0.537 & 0.406 & 0.538 & 0.487 & 0.573 & 0.447 & 0.539 & 0.508 & 0.523 & 0.830 & & & & & \\
\hline $\mathrm{SCI}$ & 0.588 & 0.496 & 0.442 & 0.508 & 0.691 & 0.621 & 0.587 & 0.496 & 0.443 & 0.512 & 0.507 & 0.529 & 0.531 & 0.818 & & & & \\
\hline FLP & 0.509 & 0.525 & 0.443 & 0.506 & 0.463 & 0.613 & 0.511 & 0.523 & 0.447 & 0.519 & 0.527 & 0.536 & 0.472 & 0.506 & 0.831 & & & \\
\hline EFP & 0.514 & 0.539 & 0.528 & 0.415 & 0.447 & 0.765 & 0.517 & 0.565 & 0.553 & 0.486 & 0.491 & 0.547 & 0.545 & 0.490 & 0.601 & 0.836 & & \\
\hline CSP & 0.484 & 0.571 & 0.444 & 0.535 & 0.419 & 0.537 & 0.492 & 0.578 & 0.452 & 0.543 & 0.501 & 0.527 & 0.461 & 0.551 & 0.531 & 0.547 & 0.801 & \\
\hline PIP & 0.586 & 0.494 & 0.442 & 0.506 & 0.691 & 0.623 & 0.594 & 0.502 & 0.448 & 0.513 & 0.603 & 0.512 & 0.467 & 0.522 & 0.519 & 0.554 & 0.572 & 0.818 \\
\hline AVE & 0.534 & 0.551 & 0.589 & 0.617 & 0.673 & 0.649 & 0.681 & 0.687 & 0.662 & 0.655 & 0.623 & 0.674 & 0.689 & 0.672 & 0.691 & 0.699 & 0.641 & 0.669 \\
\hline
\end{tabular}

Diagonal elements (bold and italic), and the off-diagonal elements represent similarities across constructions, are really the square root of the extracted average variance (AVE).

$* * * \mathrm{p}<0.001$

Source: Authors' preparation 
The separate SCMS and SCM performance designs and assessment of the single factor congeneric model accomplished this fit. These fit indices display the share of the overall fit to a null model of the given measuring model. Table 2 shows NFI values ranging from 0.922 to 0.971 and NNFI values from 0.923 to 0.977 . These values show that any building converges satisfactorily. Finally, the convergent validity of 18 structures was determined with the average extracted variance (AVE). AVE indicates the average variance from which each measurement component will draw a structure. The 18 structures have such an AVE of 0,534 to 0,699 as shown in the final row of Table 2 . The convergent validity of a structure indicates AVE of 0.5 or even more (Hair, Black, Babin, Anderson \& Tatham, 2009). All structures have a threshold level of much more than an AVE, and this shows that the structures mentioned are indeed very convergent.

\subsubsection{Discriminant validity}

Discriminatory validity measures how a structure differs from the other structures in the same type and whether each building measures various principles (Hair, Black, Babin, Anderson \& Tatham, 2009). Three various methods were also used to evaluate the legitimacy of discrimination. The first approach entails examining the association between each pair of structures in the CFA model. There seems to be little chance of a collection of objects loading substantially on one structure loading on another structure if their similarities between the buildings are well under 0.9. (Kline, 2005). None of the similarities was close to 0.9 , as seen in Table 3 . The objects are thus one-size-faced. The second procedure involves analyzing the discrepancies in Chi-square by comparing the two structures at a time between both SCMPs constructs and SCM performance. If the null hypothesis is refused, which says that together, they form one continuous construction, all constructions will be regarded separately. A comparison with a connection restricted to one with an unrestricted pattern was carried out in pairs. An important discrepancy of $p<0.05$ level between the chi-square values of both models (d.f. $=1$ ) shows support for discrimination of validity (Anderson \& Gerbing, 1988). Table 4 records the findings of a combined 153 SCMPs and SCM performance assessments discriminant validity checks. The $\mathrm{p}<0.001$ is a good indicator of support over discriminant validity for all Chi-square variations.

Table 4

Evaluation of discriminatory validity of SCMPs and SCM performance structures

\begin{tabular}{|c|c|c|c|c|c|c|c|c|c|c|c|c|c|c|c|c|c|c|}
\hline Construct & SPS & $\mathrm{CR}$ & IS & IQ & LM & TQM & $\mathrm{OC}$ & ICT & BPM & $\mathrm{AM}$ & OUT & GSCM & RL & SCI & FLP & EFP & CSP & PIP \\
\hline SPS & - & & & & & & & & & & & & & & & & & \\
\hline $\mathrm{CR}$ & 65.7 & - & & & & & & & & & & & & & & & & \\
\hline IS & 56.1 & 47.3 & - & & & & & & & & & & & & & & & \\
\hline IQ & 49.2 & 41.1 & 61.1 & - & & & & & & & & & & & & & & \\
\hline LM & 48.1 & 57.4 & 71.4 & 58.4 & - & & & & & & & & & & & & & \\
\hline TQM & 65.1 & 84.2 & 67.5 & 88.2 & 91.4 & - & & & & & & & & & & & & \\
\hline $\mathrm{OC}$ & 68.1 & 94.2 & 96.3 & 72.2 & 73.4 & 71.3 & - & & & & & & & & & & & \\
\hline ICT & 77.4 & 95.1 & 73.9 & 109.7 & 95.5 & 61.6 & 74.2 & - & & & & & & & & & & \\
\hline BPM & 94.2 & 101.1 & 124.6 & 49.5 & 94.9 & 102.4 & 61.7 & 104.3 & - & & & & & & & & & \\
\hline $\mathrm{AM}$ & 51.4 & 85.6 & 79.6 & 68.3 & 41.6 & 61.8 & 39.6 & 64.7 & 56.7 & - & & & & & & & & \\
\hline OUT & 68.5 & 87.3 & 67.9 & 88.2 & 89.4 & 74.2 & 89.2 & 67.9 & 91.3 & 91.5 & - & & & & & & & \\
\hline GSCM & 71.5 & 97.5 & 97.4 & 73.2 & 71.4 & 77.3 & 99.4 & 97.6 & 75.2 & 72.4 & 86.5 & - & & & & & & \\
\hline $\mathrm{RL}$ & 78.8 & 98.4 & 73.2 & 111.7 & 93.5 & 86.5 & 101.3 & 71.2 & 112.7 & 94.6 & 96.7 & 71.4 & - & & & & & \\
\hline $\mathrm{SCI}$ & 95.6 & 109.3 & 119.7 & 51.5 & 92.9 & 103.3 & 111.2 & 121.8 & 52.9 & 92.7 & 97.9 & 60.7 & 81.4 & - & & & & \\
\hline FLP & 53.8 & 88.7 & 81.7 & 69.3 & 37.6 & 60.7 & 91.8 & 87.8 & 71.8 & 57.1 & 91.6 & 82.2 & 100.7 & 91.5 & - & & & \\
\hline EFP & 55.5 & 86.7 & 79.5 & 72.3 & 39.6 & 62.9 & 53.6 & 74.7 & 99.6 & 89.8 & 102.3 & 99.8 & 50.5 & 90.9 & 84.7 & - & & \\
\hline CSP & 69.2 & 88.1 & 69.9 & 81.2 & 90.4 & 75.7 & 83.2 & 79.9 & 56.7 & 87.3 & 81.1 & 88.1 & 60.3 & 76.6 & 94.9 & 67.4 & - & \\
\hline PIP & 72.2 & 97.9 & 99.6 & 73.2 & 74.4 & 78.3 & 97.5 & 99.6 & 58.8 & 59.9 & 80.7 & 77.9 & 80.2 & 87.4 & 95.8 & 58.7 & 77.9 & - \\
\hline
\end{tabular}

Source: Authors' preparation

The last approach requires comparing the AVE of each structure with the mutual variance of every structure pair as shown in Table 3. The diagonal values show the square root of AVE, and the off-diagonal values show the correspondence between each pair of structures. If the square root of AVE for each structure is greater than the similarity between individual building pairs, then this means that the building accounts for more variation in the elements allocated to it (Fornell \& Larcker, 1981). Close inspection of Table 3 shows that almost all estimates of the AVE square root of the constructions seem more than corresponding to the other structures. This shows that all constructions are rather discriminatingly accurate.

\subsubsection{Nomological validity}

The objective of this test of validity is to decide whether each pair of structures in the model is in keeping with the current theory and if their similarities are meaningful and positive. In the off-diagonal elements of Table 3 , the correlation between a pair of constructs regarding SCMPs and their respective $\mathrm{p}$ values has been seen. Of 153 inter-construction correlations at $\mathrm{p}<0.001$ level, it is observed that are significant. Therefore, all inter-construction similarities can be concluded to be significant and optimistic. This phénomene means that the SCMPs and SCM scales are nomologically true (Hair, Black, Babin, Anderson \& Tatham, 2009, (Singh, Power \& Chuong, 2011).

\subsubsection{Criterion-related validity}

This validity test shows how well a level of the structures of different procedures is success associated (Ahire, Golhar \& Waller, 1996; Chen \& Paulraj, 2004). In other words, the study seeks to determine whether the association is meaningful between the predictor pair and the criteria vector. In this analysis, 14 SCMPs indicate the predictor variables containing: Strategic Partnership of Suppliers (SPS), Customer Relationships (CR), Information Sharing (IS), Information Quality (IQ), Lean Manufacturing (LM), Total Quality Management (TQM), Organizational Culture (OC), Information and 
Communication Technology (ICT), Benchmarking and Performance Measurement (BPM), Agile Manufacturing (AM), Outsourcing (OUT), Green SC Management (GSCM), Reverse Logistics (RL), SC Integration (SCI). Four SCM performance metrics represent the variables of the criterion: Flexibility Perspective (FLP), Efficiency Perspective (EFP), Customer's Perspective (CSP), Product Innovation Perspective (PIP). A partial correlation was also made, after checking for the influence of other predictor values, across each couple of a predictor variable and a criterion variable. For e.g., we monitored the influence of other 13 predictor variables to establish the partial association between SPS and FLP. For both predictor pairs and criterion factors, this exercise has been replicated. Initially, we found the reduced set of SCMPs variables and the SCM performance variables obtained by CFA. These observed SCMPs and SCM variables were subjected separately to an analysis of the factor which eventually resulted in the identical 14 SCMPs constructs and the four SCM constructs. All of these constructs have been considered as variables: the SCMPs constructs as indicator variables and the SCM performance constructs as criterion variables. A partial correlation is defined using these predictors and parameter variables. Table 5 shows this.

Table 5

Assessment of Criterion-related validity between the constructs of SCMPs and SCM performance

\begin{tabular}{|c|c|c|c|c|}
\hline \multirow[t]{2}{*}{ Predictor Variable } & \multicolumn{4}{|l|}{ Criteria Variables } \\
\hline & FLP & EFP & CSP & PIP \\
\hline SPS & $0.347(* * *)$ & $0.252(* *)$ & $0.176(* *)$ & -0.058 \\
\hline $\mathrm{CR}$ & $0.275(* * *)$ & -0.012 & $0.152(*)$ & $0.257(* * *)$ \\
\hline IS & $0.301(* * *)$ & -0.023 & $0.263(* * *)$ & -0.091 \\
\hline IQ & $0.214(* *)$ & 0.126 & -0.097 & $0.342(* * *)$ \\
\hline $\mathrm{LM}$ & -0.079 & 0.083 & 0.029 & 0.064 \\
\hline TQM & $0.188(* *)$ & $0.256(* * *)$ & $0.369(* * *)$ & $0.281(* * *)$ \\
\hline $\mathrm{OC}$ & $0.165(* *)$ & -0.027 & $0.297(* * *)$ & -0.043 \\
\hline ICT & $0.276(* * *)$ & 0.114 & $0.323(* * *)$ & -0.051 \\
\hline BPM & -0.102 & -0.026 & $0.237(* *)$ & 0.149 \\
\hline AM & 0.077 & $0.572(* * *)$ & -0.093 & 0.112 \\
\hline OUT & -0.093 & $0.299(* * *)$ & $0.187(*)$ & $0.187(*)$ \\
\hline GSCM & $0.292(* * *)$ & $0.334(* * *)$ & $0.296(* * *)$ & $0.298(* * *)$ \\
\hline RL & -0.123 & $0.248(* *)$ & -0.127 & -0.134 \\
\hline SCI & $0.378(* * *)$ & -0.109 & 0.072 & 0.081 \\
\hline
\end{tabular}

Source: Authors' preparation

The result of the whole attempt shows whether or not the interaction between a couple of a predictive variable and the criteria variable contributes to an understanding of their future correlation. Several researchers (Marrelec et al., 2007; Marrelec, Kim, Doyon \& Horwitz, 2009; Das, 2017) have followed a similar method in which partial correlations were first performed in related variables to discover that the relations were important or negligible. SEM was added to the chosen variables based on the results of partial correlations and prior literature information. Marrelec et al. (2007) and Marrelec \& Benali (2009) stated that this method would increase both the conceptual and analytical support for the results of the analysis.

The findings of these results show that out of 40 correlations 29 correlations are significant. The negligible existence of the interaction between left predictor couples and parameters indicates that they are quite unrelated and catch different components of SCMPs and SCM. For example, GSCM shows the SCM practices implemented by a company as we discuss the relationship between GSCM and PIP, while PIP reflects a company's viewpoint on product innovativeness. There seems to be no important relationship between these unrelated pairs of indicator variables and criterion variables in the existing literature. These revelations include an overview of the identification of hypothesized links between unique predictor couples and variables of requirements. At the same time, we notice the supportive evidence for almost all the important correlations achieved in this analysis as we address this in the previous subsections. There is an appropriate degree of criteria-related legitimacy for the structures of SCMPs and SCM performance. Annex B demonstrates SCMP and SCM performance for the final parsimonious measure.

\section{Discussion and implications}

The current study has attempted to combine SCMPs and SCM performance principles by taking elements from various literature. Subsequently, a scale of 14 SCMPs constructs and other four SCM performance constructs was tested and applied. The behaviour, as seen in Table 3 and stated in the nomological validity section, of these 18 structures were investigated by 153 inter-constructive correlations. In the present results, the pattern of associations is similar to the pattern of relations available in current literature. Following an in-depth examination of the 18 important correlations in Table 5, 29 of the 40 correlations are relevant, both positive and significant. The above discovery shows that, while the survey has been conducted between manufacturing and process-oriented organizations in Saudi Arabia, its activity shows a distinct pattern of ties and may therefore be used between firms, even in other countries.

The first stage of the production includes identifying literature in different disciplines that pertain to SCMPs and SCM performance. Following this, the CFA rigorously checked the instrument for uniformity, consistency, composite reliability, divergent validity, nomological validity, and criteria-related validity. CFA results in the clean-up of SCMPs and SCM performance structures from which 6 SCMPs constructs were removed. The theoretical structures underlying the standardized scale were not greatly affected. Therefore, it is considered parsimonious the tool produced in this study. The scale comprises 
14 SCMPs structures, including Strategic Partnership of Suppliers (SPS), Customer Relationships (CR), Information Sharing (IS), Information Quality (IQ), Lean Manufacturing (LM), Total Quality Management (TQM), Organizational Culture (OC), Information and Communication Technology (ICT), Benchmarking and Performance Measurement (BPM), Agile Manufacturing (AM), Outsourcing (OUT), Green SC Management (GSCM), Reverse Logistics (RL), SC Integration (SCI). The scale also includes four other SCM performance structures, including Flexibility Perspective (FLP), Efficiency Perspective (EFP), Customer's Perspective (CSP), Product Innovation Perspective (PIP).

Almost all dimensions of a given measurement are covered separately in the structures of the previous results, not all related features of SCMPs are included. The present study aimed to create a scale that includes the related SCMPs and SCM performance. The research, therefore, included in the whole SC initially all the relevant SCM items in the literature. The purification process subsequently led to the removal of some elements. This did not change the content of the magnitude substantially and at the same time retain the sparing value of the magnitude. To date, relatively few experiments have been available that have established a scale that considers the applicable buildings in both SCMPs and SCM performance. The scale built in the current study incorporates both SCMPs and SCM performance and is intended to contribute significantly to the established SCM existing literature.

Managers interested in applying SCMPs and assessing a firm's performance of the SCM could monitor the significance of SCM implementation with the assistance of this qualified instrument, could also evaluate its performance in various areas of the SCM. Based on the classification of the followed SCMPs and the performance results on various aspects of SCM, managers could advise which dimensions of SCM need increased focus by the top leaders and where additional resources are required for adequate execution and performance results. In addition, managers may, by this tool, make a judgment on the distribution of resources based on the strategic needs of an enterprise.

\section{Conclusion}

As regards the dimension of SCM performance constructs, Flexibility Perspective (FLP), Efficiency Perspective (EFP), Customer's Perspective (CSP), Product Innovation Perspective (PIP) Constructs are considered to be in keeping with the results of the current study (Gunasekaran, Patel \& McGaughey, 2004; El-Garaihy, 2021). The research contributes to the success of SCMP's and SCM's in the Saudi manufacturing sector by studying the measurement scales validity which helps management decision-makers to evaluate their organization's SCMPs and SCM performance. The research represented the consistency, authenticity, and implementation of SCMPs and SCM performance in different SCs. Furthermore, the research serves in many cases as proof of the use of SCMPs and SCM performance. The recent invention to identify SCMPs and SCM output structures may be regarded. To date, relatively little research is available which has established a scale that considers the related buildings in SCM and SCMPs. The scale built in the current study incorporates both SCM and SCMPs and is intended to contribute significantly to the established SCM literature.

This research was underway between the companies of production, refining, and manufacturing that include chemical, manufacturing, plastics, pharmacy, manufacturing, clothing, fur, shoes, paper, pulp, metal, a material manufactured, electronics and communications, electrical, mechanical, vehicle, and automotive components, boat machinery, precision machinery, etc. The study was carried out. This study considers the scale more or less widespread in nature and applies to the industries in the above categories. As for the applicable scale of some industries, including food and beverage, perishable agricultural commodities, auto components, engineered, IT and telecommunications products, textiles, consumer goods, steel and steel products processing, petroleum, gas, and oil products processing and power generation and distribution, there are special requirements for these sectors with regard to safe and secure energy production. The scale established in the latest examination should understand these factors to make the instrument relevant to the aforementioned industries. In addition, it is possible to create a different scale of SCM for the food and beverage industry or the refining of oil, gas, and oil goods, considering relevant industries. This can be used as an opportunity for potential investigation.

Several limits apply to the analysis. Firstly, the sample size of respondents of different sectors cannot be consistent, which may lead to a very prejudicial research result against a specific industry. Secondly, the selected companies are in heterogeneous markets. SCMPs are mature and range from one industry to another. The research attempted to generalize the results on the basis of the reactions of diverse industries. The results would probably have shown a more coherent trend, had the analysis been limited to one kind of industry, and the answers from certain companies that belong to that specific industry were gathered. However, the results could form the basis for future studies in this direction, since they were one of the first attempts to design a range of SCMPs and SCM performance. Finally, based on the results of the measurement model, a structural model is to be created. The structural model is intended to explore the effect on SCM performance of various aspects of SCMPs. This is considered in a different interpretation.

\section{Acknowledgement}

The authors are highly thankful to all the associated personnel who in any reference contributed to the completion of this study. Dr. El-Garaihy is on a sabbatical leave from Port Said University, Egypt.

\section{Funding}

The authors would like to thank the Deanship of Scientific Research at Imam Abdulrahman Bin Faisal University, Saudi Arabia for providing financial support for this research via grant number 2019-395-ASCS. 


\section{References}

Abdallah, A., Obeidat, B. \& Aqqad, N. (2014). The Impact of Supply Chain Management Practices on Supply Chain Performance in Jordan: The Moderating Effect of Competitive Intensity. International Business Research, 7(3), 13-27.

Ahire, S., Golhar, D. \& Waller, M. (1996). Development and Validation of TQM Implementation Constructs. Decision Sciences, 27(1), 23-56.

Al-khalifa, K. \& Aspinwall, E., 2000. The development of total quality management in Qatar. The TQM Magazine, 12(3), 194-204.

Anderson, J. \& Gerbing, D. (1988). Structural equation modeling in practice: A review and recommended two-step approach. Psychological Bulletin, 103(3), 411-423.

Anuar, A. \& Mohd Yusuff, R. (2011). Manufacturing best practices in Malaysian small and medium enterprises (SMEs). Benchmarking: An International Journal, 18(3), 324-341.

Attaran, M. (2007). RFID: an enabler of supply chain operations. Supply Chain Management: An International Journal, 12(4), 249-257.

Barney, J. (1986). Organizational Culture: Can It Be a Source of Sustained Competitive Advantage?. The Academy of Management Review, 11(3), 656-665.

Barratt, M., 2004. Understanding the meaning of collaboration in the supply chain. Supply Chain Management: An International Journal, 9(1), 30-42.

Bayraktar, E., Demirbag, M., Koh, S., Tatoglu, E. \& Zaim, H. (2009). A causal analysis of the impact of information systems and supply chain management practices on operational performance: Evidence from manufacturing SMEs in Turkey. International Journal of Production Economics, 122(1), 133-149.

Beamon, B. (1998). Supply chain design and analysis: models and methods. International Journal of Production Economics, 55(3), 281-294.

Bhagwat, R. \& Sharma, M. (2007). Performance measurement of supply chain management: A balanced scorecard approach. Computers \& Industrial Engineering, 53(1), 43-62.

Boddy, D., Macbeth, D. \& Wagner, B. (2000). Implementing Collaboration Between Organizations: An Empirical Study Of Supply Chain Partnering. Journal of Management Studies, 37(7), 1003-1018.

Chen, I. \& Paulraj, A. (2004). Towards a theory of supply chain management: the constructs and measurements. Journal of Operations Management, 22(2), 119-150.

Chen, Y., Rungtusanatham, M., Goldstein, S. \& Koerner, A. (2013). Theorizing through metaphorical transfer in OM/SCM research: Divorce as a metaphor for strategic buyer-supplier relationship dissolution. Journal of Operations Management, $31(7-8), 579-586$.

Childerhouse, P. \& Towill, D. (2003). Simplified material flow holds the key to supply chain integration. Omega, 31(1), 1727.

Chin, K., Rao Tummala, V., Leung, J. \& Tang, X. (2004). A study on supply chain management practices. International Journal of Physical Distribution \& Logistics Management, 34(6), 505-524.

Chong, A., Chan, F., Ooi, K. \& Sim, J. (2011). Can Malaysian firms improve organizational/innovation performance via SCM?. Industrial Management \& Data Systems, 111(3), 410-431.

Chow, W., Madu, C., Kuei, C., Lu, M., Lin, C. \& Tseng, H. (2008). Supply chain management in the US and Taiwan: An empirical study. Omega, 36(5), 665-679.

Christopher, M., \& Towill, D. (2000). Supply chain migration from lean and functional to agile and customised, Supply Chain Management: An International Journal, 5(4), 206-213.

Cook, L., Heiser, D. \& Sengupta, K. (2011). The moderating effect of supply chain role on the relationship between supply chain practices and performance. International Journal of Physical Distribution \& Logistics Management, 41(2), 104134.

Cox, A. (2004). The art of the possible: relationship management in power regimes and supply chains. Supply Chain Management: An International Journal, 9(5), 346-356.

Cvsa, V. \& Gilbert, S. (2002). Strategic commitment versus postponement in a two-tier supply chain. European Journal of Operational Research, 141(3), 526-543.

Dadzie, K. \& Winston, E. (2007). Consumer response to stock-out in the online supply chain. International Journal of Physical Distribution \& Logistics Management, 37(1), 19-42.

Danese, P. (2006). The extended VMI for coordinating the whole supply network. Journal of Manufacturing Technology Management, 17(7), 888-907.

Das, D. (2017). Development and validation of a scale for measuring Sustainable Supply Chain Management practices and performance. Journal of Cleaner Production, 164, 1344-1362.

Dixon, J., Nanni, A., \& Vollmann, T. (1990). The New Performance Challenge-Measuring Operations for World-Class Competition. Dow Jones-Irwin, Homewood, IL.

Donlon, J. (1996). Maximizing value in the supply chain. Chief Executive, 117(1) 54-63.

Doolen, T. \& Hacker, M. (2005). A review of lean assessment in organizations: An exploratory study of lean practices by electronics manufacturers. Journal of Manufacturing Systems, 24(1), 55-67.

Drohomeretski, E., Gouvea da Costa, S., Pinheiro de Lima, E. \& Wachholtz, H. (2012). Lean Supply Chain Management: Practices and Performance Measures. Industrial and Systems Engineering Research Conference. 
El-Garaihy, W. (2021). Effectiveness of performance measurement framework on manufacturers supply chain - case of Saudi Arabia. Journal of Facilities Management, 19(2), 174-194.

El-Garaihy, W., Badawi, U., Moawad, M. \& Azizi, T., 2020. Investigating Firm Performance Outcomes Under Interorganizational, Firm level, and Environmental Factors that Motivate Supply Chain Integration. International Journal of Innovation, Creativity \& Change, 14(12), 74-113.

Elofson, G. \& Robinson, W., 2007. Collective customer collaboration impacts on supply-chain performance. International Journal of Production Research, 45(11), 2567-2594.

Elwan Ibrahim, S. \& Ogunyemi, O. (2012). The effect of linkages and information sharing on supply chain and export performance. Journal of Manufacturing Technology Management, 23(4), 441-463.

Flynn, B., Huo, B. \& Zhao, X. (2009). The impact of supply chain integration on performance: A contingency and configuration approach. Journal of Operations Management, 28(1), 58-71.

Fornell, C. \& Larcker, D. (1981). Evaluating Structural Equation Models with Unobservable Variables and Measurement Error. Journal of Marketing Research, 18(1), 39-50.

Forslund, H. \& Jonsson, P. (2007). The impact of forecast information quality on supply chain performance. International Journal of Operations \& Production Management, 27(1), 90-107.

Garza-Reyes, J., Al-Jasser, A., Oraifige, I., Soriano-Meier, H. \& Forrester, P. (2011). A general evaluation of total quality management (TQM) in the Kuwait oil industry. Proceedings of the 21st International Conference on Flexible Automation and Intelligent Manufacturing (FAIM), Taichung, 26-29 June.

Garza-Reyes, J., Parkar, H., Oraifige, I., Soriano-Meier, H.\& Harmanto, D. (2012). An empirical-exploratory study of the status of lean manufacturing in India. International Journal of Business Excellence, 5(4), 395-412.

Gawankar, S., Kamble, S. \& Raut, R. (2017). An investigation of the relationship between supply chain management practices (SCMP) on supply chain performance measurement (SCPM) of Indian retail chain using SEM. Benchmarking: An International Journal, 24(1), 257-295.

Gawankar, S., Kamble, S. \& Verma, R. (2013). Development, measurement and validation of supply chain management practices scale in Indian retail sector. International Journal of Procurement Management, 6(5), 495-522.

Gerbing, D. \& Anderson, J. (1988). An Updated Paradigm for Scale Development Incorporating Unidimensionality and Its Assessment. Journal of Marketing Research, 25(2), 186-192.

Gharakhani, D., Mavi, R. \& Hamidi, N. (2012). Impact of supply chain management practices on innovation and organizational performance in Iranian companies. African Journal of Business Management, 6(19), 5939-5949.

Gorane, S. \& Kant, R. (2016). Supply chain practices. Benchmarking: An International Journal, 23(5), 1076-1110.

Gosselin, M. (2005). An empirical study of performance measurement in manufacturing firms. International Journal of Productivity and Performance Management, 54(5/6), 419-437.

Guide, V., Jayaraman, V., Srivastava, R. \& Benton, W. (2000). Supply-Chain Management for Recoverable Manufacturing Systems. Interfaces, 30(3), 125-142.

Gunasekaran, A., \& Kobu, B. (2007). Performance measures and metrics in logistics and supply chain management: a review of recent literature (1995-2004) for research and applications. International Journal of Production Research, 45(12), 2819-2840.

Gunasekaran, A., Patel, C. \& McGaughey, R. (2004). A framework for supply chain performance measurement. International Journal of Production Economics, 87, 333-347.

Gunasekaran, A., Patel, C., \& Tirtiroglu, E. (2001). Performance measure and metrics in a supply chain environment. International Journal of Operations \& Production Management, 21(1/2), 71-87.

Gustavsson, M. (2008). Information quality implications of planning process integration. Journal of Manufacturing Technology Management, 19(8), 933-952.

Hair J, Black, W., Babin, B., Anderson, R. \& Tatham, R. (2009). Multivariate Data Analysis. $6^{\text {th }}$ ed. Pearson Education, New Delhi.

Hair, J., Ringle, C. \& Sarstedt, M. (2011). PLS-SEM: Indeed, a Silver Bullet. Journal of Marketing Theory and Practice, $19(2), 139-152$.

Hendry, J. (1995). Culture, community and networks: The hidden cost of outsourcing. European Management Journal, 13(2), 193-200.

Hervani, A., Helms, M. \& Sarkis, J. (2005). Performance measurement for green supply chain management. Benchmarking: An International Journal, 12(4), 330-353.

Hines, P., Holweg, M. \& Rich, N. (2004). Learning to evolve. International Journal of Operations \& Production Management, 24(10), 994-1011.

Holt, D. \& Ghobadian, A. (2009). An empirical study of green supply chain management practices amongst UK manufacturers. Journal of Manufacturing Technology Management, 20(7), 933-956.

Hsu, C., Tan, K., Kannan, V. \& Keong Leong, G. (2009). Supply chain management practices as a mediator of the relationship between operations capability and firm performance. International Journal of Production Research, 47(3), 835-855.

Ismail Salaheldin, S. (2005). JIT implementation in Egyptian manufacturing firms: some empirical evidence. International Journal of Operations \& Production Management, 25(4), 354-370.

Jabnoun, N. (2002). Control processes for total quality management and quality assurance. Work Study, 51(4), 182-190.

Jraisat, L. \& Sawalha, I., 2013. Quality control and supply chain management: a contextual perspective and a case study. Supply Chain Management: An International Journal, 18(2), 194-207. 
Kaplan, R. \& Norton, D., 1992. The balanced scorecard measures that drive performance. Harvard Business Review, 70 (January-February), 71-79.

Kayakutlu, G. \& Büyüközkan, G., 2010. Effective supply value chain based on competence success. Supply Chain Management: An International Journal, 15(2), 129-138.

Keegan, D., Eiler, R. \& Jones, C. (1989). Are your performance measures obsolete?. Management Accounting, 70(12) 4550.

Kleindorfer, P.R., \& Van Wassenhove, W.L.N. (2004). “Managing risk in global supply chains”, in Gatigon, H. and Kimberly, J. (Eds), Strategies for Building Successful Global Businesses. Cambridge University Press, pp. $288-305$.

Kline, R. (2005). Principles and practice of structural equation modeling. $2^{\text {nd }}$ ed. New York: Guilford Press.

Krause, D., Scannell, T. \& Calantone, R. (2000). A Structural Analysis of the Effectiveness of Buying Firms' Strategies to Improve Supplier Performance. Decision Sciences, 31(1), 33-55.

Kumar, P. \& Kumar, M. (2003). Vendor managed inventory in retail industry. white paper, Tata Consultancy Services

Lee, D. \& Park, J. (2008). RFID-based traceability in the supply chain. Industrial Management \& Data Systems, 108(6), 713725.

Lenny Koh, S., Demirbag, M., Bayraktar, E., Tatoglu, E. \& Zaim, S. (2007). The impact of supply chain management practices on performance of SMEs. Industrial Management \& Data Systems, 107(1), 103-124.

Leończuk, D., Ryciuk, U., Szymczak, M., \& Nazarko J. (2019). Measuring performance of adaptive supply chains, in: A. Kawa, A. \& Maryniak (Eds), SMART Supply Network, EcoProduction (Environmental Issues in Logistics and Manufacturing). Springer, Cham.

Li, S., Ragu-Nathan, B., Ragu-Nathan, T. \& Subba Rao, S. (2006). The impact of supply chain management practices on competitive advantage and organizational performance. Omega, 34(2), 107-124.

Li, S., Rao, S., Ragu-Nathan, T. \& Ragu-Nathan, B. (2005). Development and validation of a measurement instrument for studying supply chain management practices. Journal of Operations Management, 23(6), 618-641.

Li, Z., Xu, X., \& Kumar, A. (2007). Supply Chain Performance Evaluation from Structural and Operational Level. " paper presented at the IEEE conference on emerging technologies and factory automation (EFTA), Patras, Greec,1, 1131-40.

Lopes de Sousa Jabbour, A., Gomes Alves Filho, A., Backx Noronha Viana, A. \& José Chiappetta Jabbour, C. (2011). Measuring supply chain management practices. Measuring Business Excellence, 15(2), 18-31.

Lummus, R., Duclos, L. \& Vokurka, R. (2003). Supply chain flexibility: building a new model. Global Journal of Flexible Systems Management, 4(4), 1-13.

Luthra, S., Kumar, V., Kumar, S. \& Haleem, A. (2011). Barriers to implement green supply chain management in automobile industry using interpretive structural modeling technique: An Indian perspective. Journal of Industrial Engineering and Management, 4(2), 231-257.

Lyons, A., Mondragon, A., Piller, F. \& Poler, R. (2012). Customer-Driven Supply Chains: From Glass Pipelines to Open Innovation Networks, Springer Science and Business Media.

MacKenzie, S. \& Podsakoff, P. (2012). Common Method Bias in Marketing: Causes, Mechanisms, and Procedural Remedies. Journal of Retailing, 88(4), 542-555.

Mahbubul, H. \& Rafikul, I. (2013). Effects of supply chain management practices on customer satisfaction: Evidence from pharmaceutical industry of Bangladesh. Global Business and Management Research: An International Journal, 5(2-3), 120-136.

Marrelec, G. \& Benali, H. (2009). A theoretical investigation of the relationship between structural equation modeling and partial correlation in functional MRI effective connectivity. Comput. Intell. Neurosci.

Marrelec, G., Horwitz, B., Kim, J., Pélégrini-Issac, M., Benali, H. \& Doyon, J. (2007). Using partial correlation to enhance structural equation modeling of functional MRI data. Magnetic Resonance Imaging, 25(8), 1181-1189.

Marrelec, G., Kim, J., Doyon, J. \& Horwitz, B. (2009). Large-scale neural model validation of partial correlation analysis for effective connectivity investigation in functional MRI. Human Brain Mapping, 30(3), 941-950.

McIvor, R. (2000). A practical framework for understanding the outsourcing process. Supply Chain Management: An International Journal, 5(1), 22-36.

Michael, K. \& McCathie, L. (2005). The pros and cons of RFID in supply chain management in mobile business. ICMB. International Conference on IEEE, July, 623-629.

Mileham, A., Culley, S., Owen, G. \& Mcintosh, R. (1999). Rapid changeover - a pre-requisite for responsive manufacture. International Journal of Operations \& Production Management, 19(8), 785-796.

Min, S. \& Mentzer, J. (2001). The role of marketing in supply chain management. International Journal of Physical Distribution and Logistics Management, 30(9), 766-787.

Min, S. \& Mentzer, J. (2004). Developing And Measuring Supply Chain Management Concepts. Journal of Business Logistics, 25(1), 63-99.

Moberg, C., Cutler, B., Gross, A. \& Speh, T. (2002). Identifying antecedents of information exchange within supply chains. International Journal of Physical Distribution \& Logistics Management, 32(9), 755-770.

Mohd, N. (2007). Supply Chain Innovations: Creating Value for Sustained Competitive Advantage. PCTE Journal of Business Administration, 4(1), 61-66.

Mohammad Mosadeghrad, A. (2014). Why TQM programmes fail? A pathology approach. The TQM Journal, 26(2), 160187. 
Morali, O. \& Searcy, C. (2013). A Review of Sustainable Supply Chain Management Practices in Canada. Journal of Business Ethics, 117(3), 635-658.

Näslund, D. \& Hulthen, H. (2012). Supply chain management integration: a critical analysis. Benchmarking: An International Journal, 19(4/5), 481-501.

Nasurdin, A., Hemdi, M.A. \& Guat, L. (2008). Does perceived organisational support mediate the relationship between human resource management practices and organisational commitment?. Asian Academy of Management Journal, 13(1), 15-36.

Neely, A., Gregory, M. \& Platts, K. (1995). Performance measurement system design. International Journal of Operations \& Production Management, 15(4), 80-116.

Nunnally, J. (1978). Psychometric Theory, $2^{\text {nd }}$ ed. McGraw Hill, New York.

Okongwu, U., Brulhart, F. \& Moncef, B., 2015. Causal linkages between supply chain management practices and performance. Journal of Manufacturing Technology Management, 26(5), 678-702.

Othman, P., Sungkar, I. \& Sabri Wan Hussin, W. (2009). Malaysia as an International Halal Food Hub: Competitiveness and Potential of Meat-based Industries. Asean Economic Bulletin, 26(3), 306-320.

Ou, C., Liu, F., Hung, Y. \& Yen, D. (2010). A structural model of supply chain management on firm performance. International Journal of Operations \& Production Management, 30(5), 526-545.

Pandiyan Kaliani Sundram, V., Razak Ibrahim, A. \& Chandran Govindaraju, V. (2011). Supply chain management practices in the electronics industry in Malaysia. Benchmarking: An International Journal, 18(6), 834-855.

Pandiyan Kaliani Sundram, V., Chandran, V. \& Awais Bhatti, M. (2016). Supply chain practices and performance: the indirect effects of supply chain integration. Benchmarking: An International Journal, 23(6), 1445-1471.

Park, J., Shin, K., Chang, T. \& Park, J. (2010). An integrative framework for supplier relationship management. Industrial Management \& Data Systems, 110(4), 495-515.

Paulraj, A., Chen, I. \& Lado, A. (2012). An Empirical Taxonomy of Supply Chain Management Practices. Journal of Business Logistics, 33(3), 227-244.

Podsakoff, P., MacKenzie, S., Lee, J. \& Podsakoff, N. (2003). Common method biases in behavioral research: A critical review of the literature and recommended remedies. Journal of Applied Psychology, 88(5), 879-903.

Power, D. \& Simon, A. (2004). Adoption and diffusion in technology implementation: a supply chain study. International Journal of Operations \& Production Management, 24(6), 566-587.

Qrunfleh, S., Tarafdar, M. \& Ragu-Nathan, T. (2012). Examining alignment between supplier management practices and information systems strategy. Benchmarking: An International Journal, 19(4/5), 604-617.

Qrunfleh, S. \& Tarafdar, M. (2013). Lean and agile supply chain strategies and supply chain responsiveness: the role of strategic supplier partnership and postponement. Supply Chain Management: An International Journal, 18(6), 571-582.

Quinn, R. \& Rohrbaugh, J. (1983). A Spatial Model of Effectiveness Criteria: Towards a Competing Values Approach to Organizational Analysis. Management Science, 29(3), 363-377.

Ritchie, B. \& Brindley, C. (2007). Supply chain risk management and performance. International Journal of Operations \& Production Management, 27(3), 303-322.

Robb, D., Xie, B. \& Arthanari, T. (2008). Supply chain and operations practice and performance in Chinese furniture manufacturing. International Journal of Production Economics, 112(2), 683-699.

Rudberg, M. \& Olhager, J. (2003). Manufacturing networks and supply chains: an operations strategy perspective. Omega, 31(1), 29-39.

Saeed, K., Malhotra, M. \& Abdinnour, S., 2019. How supply chain architecture and product architecture impact firm performance: An empirical examination. Journal of Purchasing and Supply Management, 25(1), 40-52.

Sakka, O. \& Botta-Genoulaz, V. (2009). A model of Factors Influencing the Supply Chain Performance. hal-00389134.

Savsar, M. (1997). Simulation analysis of maintenance policies in just-in-time production systems. International Journal of Operations \& Production Management, 17(3), 256-266.

Schoenherr, T. \& Swink, M. (2011). Revisiting the arcs of integration: Cross-validations and extensions. Journal of Operations Management, 30(1-2), 99-115.

Sezen, B. (2008). Relative effects of design, integration and information sharing on supply chain performance. Supply Chain Management: An International Journal, 13(3), 233-240.

Shepherd, C. \& Günter, H. (2006). Measuring supply chain performance: current research and future directions. International Journal of Productivity and Performance Management, 55(3/4), 242-258.

Singh, P., Power, D. \& Chuong, S. (2011). A resource dependence theory perspective of ISO 9000 in managing organizational environment. Journal of Operations Management, 29(1-2), 49-64.

Slack, N. (2005). The flexibility of manufacturing systems. International Journal of Operations and Production Management, 25(12), 1190-1200.

Spekman, R., Kamauff, J. \& Myhr, N. (1998). An empirical investigation into supply chain management: a perspective on partnerships. Supply Chain Management: An International Journal, 3(2), 53-67.

Srivastava, S. (2006). Logistics and Supply Chain Practices in India. Vision: The Journal of Business Perspective, 10(3), 6979.

Stein, T. \& Sweat, J. (1998). Killer supply chains. Information Week, 708(9), 36-46.

Stonebraker, P. \& Liao, J. (2004). Environmental turbulence, strategic orientation. International Journal of Operations \& Production Management, 24(10), 1037-1054. 
Sukati, I., Hamid, A., Baharun, R. \& Yusoff, R. (2012). The Study of Supply Chain Management Strategy and Practices on Supply Chain Performance. Procedia - Social and Behavioral Sciences, 40, 225-233.

Talib, F., Rahman, Z. \& Qureshi, M. (2011). A study of total quality management and supply chain management practices. International Journal of Productivity and Performance Management, 60(3), 268-288.

Talib, F. \& Rahman, Z. (2010). Studying the impact of total quality management in service industries. International Journal of Productivity and Quality Management, 6(2), 249-264.

Tan, K., Kannan, V. \& Handfield, R. (1998). Supply chain management: supplier performance and firm performance. International Journal of Purchasing and Materials Management, 34(3), 2-9.

Tan, K., Lyman, S. \& Wisner, J. (2002). Supply chain management: a strategic perspective. International Journal of Operations \& Production Management, 22(6), 614-31.

Tan, K. (2001). A framework of supply chain management literature. European Journal of Purchasing \& Supply Management, 7(1), 39-48.

Tan, K. (2002). Supply Chain Management: Practices, Concerns, and Performance Issues. The Journal of Supply Chain Management, 38(1), 42-53.

Taylor, D. (2004). Supply Chains: a Manager's Guide, Addison-Wesley Professional, Boston.

Tripathi, S. \& Gupta, M. (2019). A current review of supply chain performance measurement systems. In Advances in Industrial and Production Engineering, Springer, Singapore, 27-39.

Trkman, P. \& Groznik, A. (2006). Measurement of Supply Chain Integration Benefits. Interdisciplinary Journal of Information, Knowledge, and Management, 1, 37-45.

Vachon, S. \& Klassen, R. (2006). Extending green practices across the supply chain. International Journal of Operations \& Production Management, 26(7), 795-821.

Wadhwa, S., Kanda, A. \& Bhoon, K. (2006). Impact of supply chain collaboration on customer service level and working capital. Global Journal of Flexible Systems Management, 7(1/2), 27-35.

Wei Khong, K. (2005). The perceived impact of successful outsourcing on customer service management. Supply Chain Management: An International Journal, 10(5), 402-411.

Wong, A., Tjosvold, D., Wong, W. \& Liu, C. (1999). Relationships for quality improvement in the Hong Kong-China supply chain. International Journal of Quality \& Reliability Management, 16(1), 24-41.

Wook Kim, S. \& Narasimhan, R. (2002). Information system utilization in supply chain integration efforts. International Journal of Production Research, 40(18), 4585-4609.

Wook Kim, S. (2006). Effects of supply chain management practices, integration and competition capability on performance. Supply Chain Management: An International Journal, 11(3), 241-248.

Yang, B., Yang, Y. \& Wijngaard, J. (2007). Postponement: an inter-organizational perspective. International Journal of Production Research, 45(4), 971-988.

Yew Wong, C., Stentoft Arlbjørn, J. \& Johansen, J. (2005). Supply chain management practices in toy supply chains. Supply Chain Management: An International Journal, 10(5), 367-378.

Zairi, M. (1998). Best practice in supply chain management: the experience of the retail sector. European Journal of Innovation Management, 1(2), 59-66

Zhang, Q., Vonderembse, M. \& Cao, M. (2006). Achieving flexible manufacturing competence: the roles of advanced manufacturing technology and operations improvement practices. International Journal of Operations \& Production Management, 26(6), 580-599.

Zhao, X., Xie, J. \& Zhang, W. (2002). The impact of information sharing and ordering co-ordination on supply chain performance. Supply Chain Management: An International Journal, 7(1), 24-40.

Zhou, H. \& Benton, W. (2007). Supply chain practice and information sharing. Journal of Operations Management, 25(6), 1348-1365.

Zhu, Q., Sarkis, J. \& Lai, K. (2008). Confirmation of a measurement model for green supply chain management practices implementation. International Journal of Production Economics, 111(2), 261-273. 


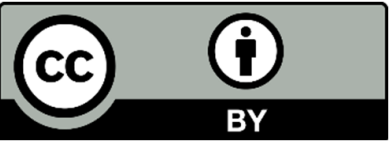

(C) 2022 by the authors; licensee Growing Science, Canada. This is an open access article distributed under the terms and conditions of the Creative Commons Attribution (CCBY) license (http://creativecommons.org/licenses/by/4.0/). 